\title{
A New Radiological Risk Containment Procedure in Potentially Contaminated Areas
}

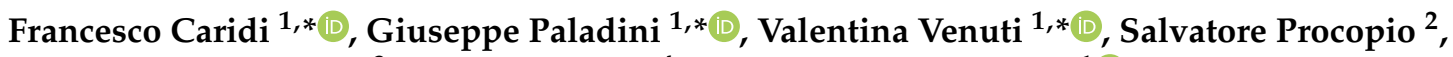 \\ Michelangelo Iannone ${ }^{3}$, Vincenza Crupi ${ }^{4}$ and Domenico Majolino ${ }^{1}$ (i)
}

1 Dipartimento di Scienze Matematiche e Informatiche, Scienze Fisiche e Scienze della Terra, Università degli Studi di Messina, Viale Ferdinando Stagno D’Alcontres 31, 98166 Messina, Italy; dmajolino@unime.it

2 Dipartimento di Catanzaro, Agenzia Regionale per la Protezione dell'Ambiente della Calabria (ARPACal), Via Lungomare (Località Giovino), 88100 Catanzaro, Italy; s.procopio@arpacal.it

3 Direzione Scientifica, Agenzia Regionale per la Protezione dell'Ambiente della Calabria (ARPACal), Via Lungomare (Località Giovino), 88100 Catanzaro, Italy; iannone@arpacal.it

4 Dipartimento di Scienze Chimiche, Biologiche, Farmaceutiche ed Ambientali, Università degli Studi di Messina, Viale Ferdinando Stagno D'Alcontres 31, 98166 Messina, Italy; vcrupi@unime.it

* Correspondence: fcaridi@unime.it (F.C.); gpaladini@unime.it (G.P.); vvenuti@unime.it (V.V.)

Citation: Caridi, F.; Paladini, G.; Venuti, V.; Procopio, S.; Iannone, M.; Crupi, V.; Majolino, D. A New Radiological Risk Containment Procedure in Potentially

Contaminated Areas. Appl. Sci. 2022, 12, 32. https://doi.org/10.3390/ app12010032

Academic Editor: Richard Kouzes

Received: 30 November 2021

Accepted: 20 December 2021

Published: 21 December 2021

Publisher's Note: MDPI stays neutral with regard to jurisdictional claims in published maps and institutional affiliations.

Copyright: (c) 2021 by the authors. Licensee MDPI, Basel, Switzerland. This article is an open access article distributed under the terms and conditions of the Creative Commons Attribution (CC BY) license (https:// creativecommons.org/licenses/by/ $4.0 /)$.

\begin{abstract}
A new radiological risk containment procedure, developed to manage the radiological risk in potentially contaminated areas, is presented here. This new methodological approach, systematically employed in sampling and site inspection activities in unknown areas from an environmental point of view, allowed the discovery of eight ${ }^{226} \mathrm{Ra}$ orphan sources buried under the road surface, in a good state of conservation, in an industrial area of the Calabrian territory, southern Italy, and they are reported here as a case study. For workers performing sampling activities in areas for which information regarding the possible presence of contaminated material is missing, an in situ radiometric check is usually carried out as a potential radiological risk prevention, by measuring the levels of environmental radioactivity. Other than this, the procedure described in this article includes, as novelty, a series of progressive operations never carried out before all together for outdoor activities: the assessment of the presence (if any) of hot spots by recording radiometric anomalies, outdoor gamma spectrometry measurements in order to identify the radionuclides generating those anomalies, the sources unearthing activities, the management of the material found and the application of a risk containment protocol.
\end{abstract}

Keywords: environment; radioactivity; orphan sources; radiological risk; dose rate; gamma spectrometry; professionally exposed workers; population

\section{Introduction}

The term "orphan sources" typically refers to radioactive sources that were never subject to regulatory control; sources that were subject to regulatory control but, after that, have been abandoned, lost or misplaced; sources that were stolen or removed without proper authorization [1,2]. Orphan radioactive sources or other radioactive materials are sometimes unintentionally collected as scrap metal destined for recycling [3,4]. Over the past decades, there have been several accidents involving such materials. These accidents exposed individuals to radiation and lead to harmful environmental, social and economic impacts [5-7].

The potentialities of an automatic radiometric control to check for any anomaly, with the help of radiometric portals installed in the plants dedicated to the treatment of hazardous wastes, are well known and widely reported in the literature [8-10].

From a general point of view, the radiometric characterization of a contaminated site is a difficult topic to deal with. In fact, not only the scenarios that can be imagined are innumerable, but the purposes for which such a characterization must be carried out can decisively influence the approach [11]. It is therefore very important, before developing a possible work plan for the characterization of a contaminated site, to clarify the final 
aim of the investigation [12], in view of an optimal use of available resources, both human and instrumental [13]. On one hand, the purpose can be, for instance, to verify if a site is actually contaminated by radioactive substances as a consequence of a deliberate and illegal disposal. On the other hand, if the sources of contamination are completely known, the main effort will be directed towards the evaluation, as accurate as possible, of the spatial and temporal characteristics of the distribution of the contamination itself, in order to achieve a dosimetric evaluation able to give an estimation of the radiological risk [14]. Apart from these two extreme conditions, a whole series of intermediate situations can be hypothesized.

In this study, an innovative radiological risk containment procedure in the environmental field is described. It consists of a series of progressive operations, well known in the context of nuclear power plants and wastes treatment, but never carried out before all together for outdoor activities. This procedure, called RADREM-RADiometric REMediation - is the result of a prevention activity for workers and the population, implemented in industrial sites or abandoned areas where the type and nature of any contamination is uncertain. Its application, as a case study, in an industrial area of about 10 hectares, located in the Vibo Valentia province, into the Calabrian territory, southern Italy [15], led to the discovery of eight ${ }^{226} \mathrm{Ra}$ orphan sources buried under the road surface. It is important to emphasize that, when we talk about the contamination of a site, we usually refer to a chemical contamination, without taking into consideration any radioactive one. Therefore, the systematic application of this procedure allows to pay attention to an aspect that is usually overlooked but that could considerably increase the health risk of the workers and the population.

\section{Materials and Methods}

\subsection{Background and Methodology}

The origin of a radioactive contamination is an aspect of extreme importance, that also influences the methods of carrying out the investigation. Its knowledge, in fact, often allows us to know, or hypothesize with reasonable certainty, the radiometric characteristics of the contamination itself [16]. However, it is difficult to make an exhaustive list of the various possible sources of radioactive contamination of a generic site. In many cases, the origin of the contamination is not known and it is indeed the investigation itself that must help to understand it. In a situation in which it is assumed or has been ascertained an unlawful activity regarding the dumping of waste, the origin of a radioactive contamination can be linked to one or more of the following causes:

- $\quad$ Trafficking or disposal of real radioactive sources, i.e., metal objects, sealed, even very small in size but with very high radioactivity values, possibly still contained within metal shields;

- Traffic or disposal of radiocontaminated materials, that is, bulk material of various origins (metal pieces, foundry slag, demolition rubble, medical waste, etc.) that at different moments of its production cycle came into contact with unsealed radioactive materials;

- Traffic or disposal of products or residues deriving from particular work activities involving the use of radioactive materials of natural origin (NORM);

- Traffic or disposal of nuclear fuel cycle materials.

In addition, the identification of the involved radionuclides is, from a technical point of view, the main question to define when planning. The nature of the radionuclides themselves, as well as their physical state, decisively influence the carrying out of the investigation. As a matter of fact, the sampling protocols, the choice of measurement techniques to be used, as well as the overall rating criteria depend on it.

The innovative radiological risk containment procedure reported in the present paper is based on the preventive verification of environmental radioactivity levels through measurements of the absorbed dose rate, with the aim of: 
1. Estimating the environmental radioactivity background level in the area of interest, through absorbed dose rate measurements performed at a height of $1 \mathrm{~m}$ above the ground level. For this purpose, the portable battery charged pressurized ion chamber survey meter, LUDLUM $9 \mathrm{DP}, 0-50 \mathrm{mSv} / \mathrm{h}$ dose rate range, $60 \mathrm{keV}-1.25 \mathrm{MeV}$ energy range, was employed [17]. All readings, at a distance of $1 \mathrm{~m}$ from each other, were performed through a transect that covered the region of interest. Ten readings, of $600 \mathrm{~s}$ each, were taken at each point of the transect and the average was recorded [18].

2. Assessing the presence (if any) of hot spots, by recording radiometric anomalies. In particular, the radiometric anomaly, $\Delta$, is defined as a significant increase in the environmental radioactivity background level, outside the acceptability value of the absorbed dose rate given by [19]:

$$
\Delta\left(n G y h^{-1}\right)=\dot{D}_{b k g}+3 \sigma_{b k g}
$$

where $\dot{D}_{b k g}$ is the average value of the environmental background dose rate and $\sigma_{b k g}$ its standard deviation.

3. Performing gamma spectrometry measurements to identify the radionuclides that generate those anomalies. For this aim, the portable Canberra InSpector $1000 \mathrm{NaI}$ spectrometer was employed [20]. It is a high-performance detector, designed to be used in all types of environmental conditions, with a high-resolution LCD color display, clearly visible from bright sunlight to night conditions. For applications requiring flexible positioning of the detector relative to the object being inspected, the detector can be detached from the instrument body and placed in any position or narrow gap. This greatly increases the probability of detecting small amounts of radiation and precisely locating sources by reducing the measurement distance. The spectrometer works in the energy range $30 \mathrm{keV}-1.4 \mathrm{MeV}$, with a resolution of $3.5 \%$ at the reference peak $\left({ }^{137} \mathrm{Cs}\right.$ at $\left.661.66 \mathrm{keV}\right)$. It can also be used as a dose rate meter, in particular for contact measurements [20].

After the identification of the radionuclide, the type of source has to be characterized. In this regard, a search for metal parts was carried out with a metal detector to evaluate the presence of steel casings.

4. Managing radiological risk, with the purpose to contain it through activities aimed at recovering the radioactive source and at managing the discovery by applying legal provisions. In particular, to quantify the activity, $A$, of a bared radioactivity source, supposed to be point-like and isotropic, the following formula was employed [21]:

$$
A(B q)=\frac{d^{2}}{\gamma} \cdot \dot{D}
$$

where $d$ is the distance between the source and the detector, $\gamma$ is the gamma constant in air for a specific radionuclide $\left(\mathrm{Gy} \mathrm{m} \mathrm{m}^{2} \mathrm{~h}^{-1} \mathrm{~Bq}^{-1}\right)$ and $\dot{D}$ is the measured absorbed dose rate [22].

\subsection{The Investigated Site}

The investigated site is shown in Figure 1. This area was in an evident and advanced state of neglect, hosting waste of different origins and hazards. It was an industrial complex consisting of warehouses, about $7500 \mathrm{~m}^{2}$, asphalt yards and unpaved areas that allow access to other buildings on the site and a built-up part intended for administrative offices. A photo of the intervention area is also reported as an inset. 


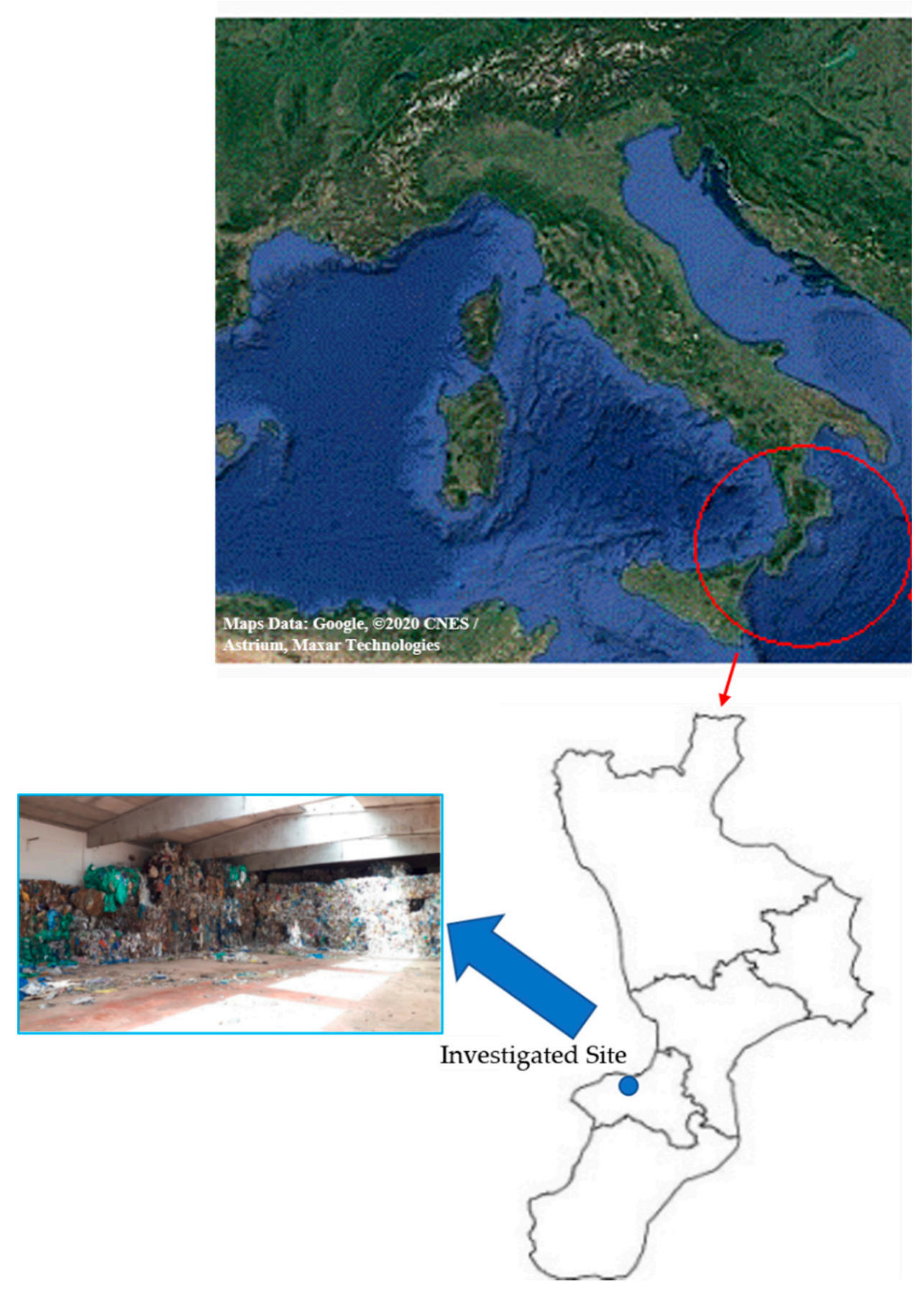

Figure 1. Map of the Calabria region (Italy), with the location of the investigated site $\left(38^{\circ} 42^{\prime} 39.50^{\prime \prime} \mathrm{N}\right.$, $\left.16^{\circ} 04^{\prime} 57.01^{\prime \prime} \mathrm{E}\right)$ indicated.

Its geolithological map, reported in Figure 2, highlights how the site of interest is classified with the hydraulic risk level R4, on a 4-level scale [23], in terms of the probability that an adverse potentially destructive phenomenon can occur within a given time and over an area. 

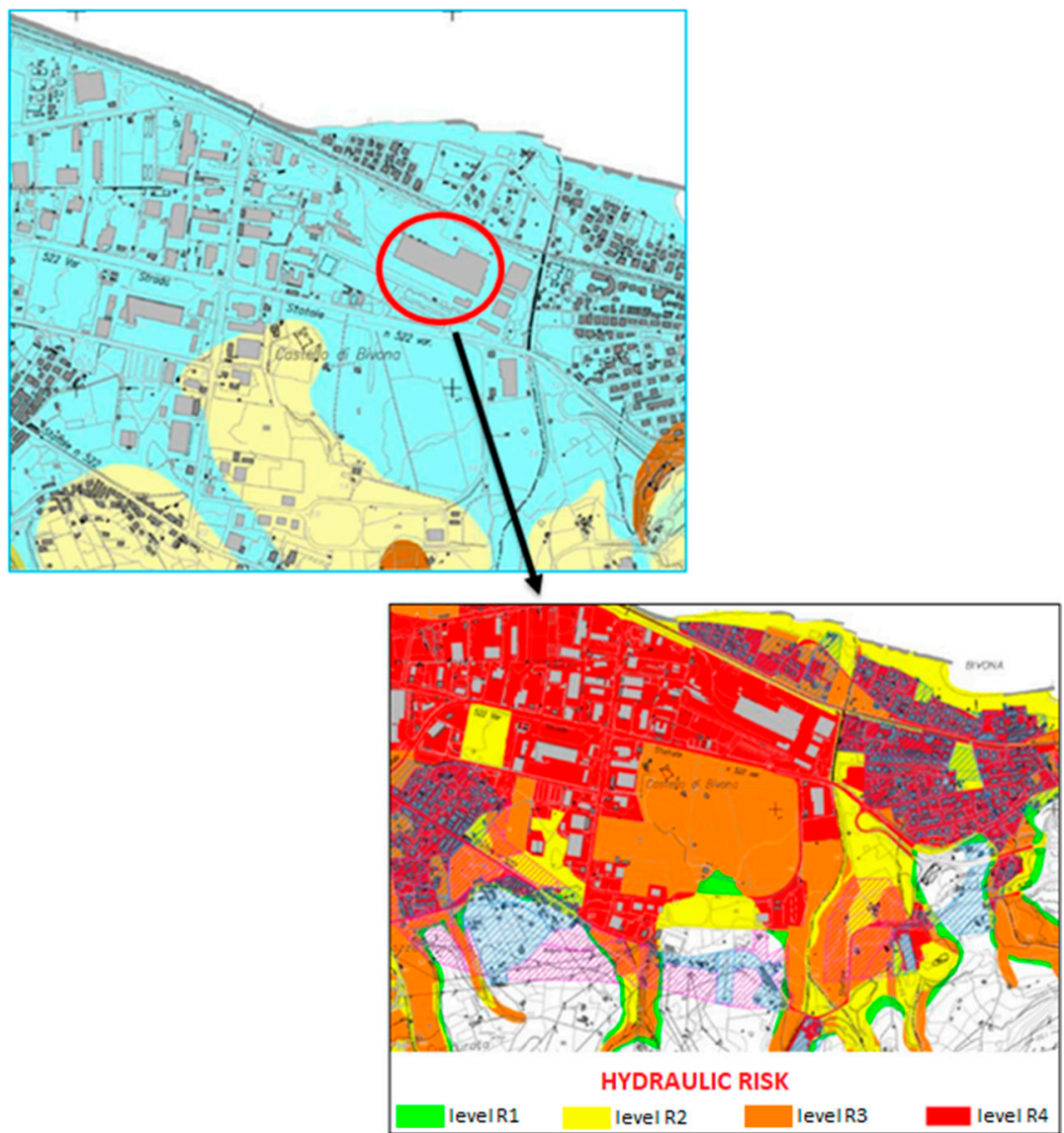

Figure 2. The geolithological map, with the hydraulic risk levels $(R \#, \#=1, \ldots, 4)$ indicated.

Therefore, the hydraulic vocation of the site of interest strongly conditioned and justified the safety measures and the unearthing of the sources.

\section{Results and Discussion}

The average value of the environmental radioactivity background measured in the investigated area was $(96 \pm 7) \mathrm{nGy} \mathrm{h}^{-1}$, in good agreement with the average values in the same area reported in the literature [24] (RADREM-stage 1).

Measurements of the absorbed dose rate made possible the identification of a part of the asphalt road, consisting in an area of about $30 \mathrm{~m}^{2}$, affected by an important radiometric anomaly at some specific points, called "hot spots", where a significant increase in the environmental radioactivity background level was recorded (RADREM-stage 2).

The "hot spots" sites are reported in Table 1, together with their IDs, GPS coordinates and average values of the measured absorbed dose rate.

Table 1. The "hot spots" sites, together with their IDs, GPS coordinates and average values of the measured absorbed dose rate.

\begin{tabular}{cccc}
\hline \multirow{2}{*}{ Site ID } & \multicolumn{2}{c}{ GPS Position } & $\begin{array}{c}\dot{\boldsymbol{D}} \\
\left(\mu \mathrm{GG} \mathbf{h}^{-\mathbf{1}}\right)\end{array}$ \\
\cline { 2 - 3 } & Latitude & Longitude & $1.6 \pm 0.1$ \\
\hline 1 & $38^{\circ} 42^{\prime} 39.06^{\prime \prime} \mathrm{N}$ & $38^{\circ} 42^{\prime} 39.12^{\prime \prime} \mathrm{N}$ & $0.4 \pm 0.1$ \\
2 & $38^{\circ} 42^{\prime} 38.98^{\prime \prime} \mathrm{N}$ & $38^{\circ} 42^{\prime} 40.81^{\prime \prime} \mathrm{N}$ & $2.8 \pm 0.2$ \\
3 & $16^{\circ} 04^{\prime} 56.95^{\prime \prime} \mathrm{E}$ & $16^{\circ} 04^{\prime} 56.95^{\prime \prime} \mathrm{E}$ & $4.8 \pm 0.4$ \\
\hline & $16^{\circ} 04^{\prime} 57.07^{\prime \prime} \mathrm{E}$ & $16^{\circ} 04^{\prime} 57.10^{\prime \prime} \mathrm{E}$ & \\
\hline
\end{tabular}

The identification of the "hot spots" allowed us to proceed to stage 3 of the RADREM: an in-depth study, performed through the use of the portable gamma spectrometer, with the 
aim to recognize the radioisotopes responsible for the radiometric anomaly. As shown in Figure 3, for the site ID1 as an example, the spectral analysis put into evidence the presence of ${ }^{226} \mathrm{Ra}$ in all the "hot spots", through the identification of its $\gamma$-line at $186.21 \mathrm{keV}$ and those of its daughters ${ }^{214} \mathrm{~Pb}$ and ${ }^{214} \mathrm{Bi}$ at $77.10 \mathrm{keV}, 295.22 \mathrm{keV}, 351.93 \mathrm{keV}$ and $609.31 \mathrm{keV}$, respectively.

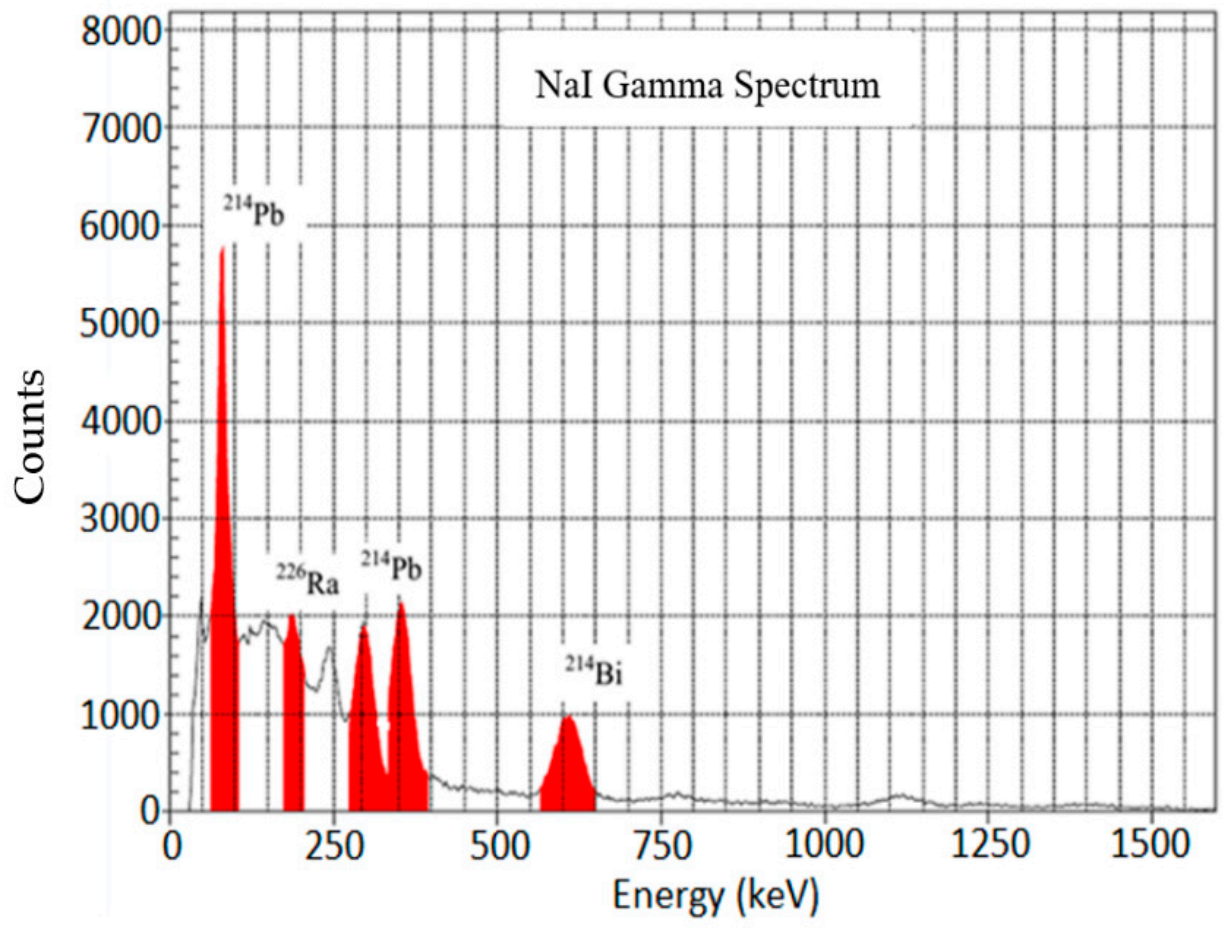

Figure 3. The Canberra InSpector $1000 \mathrm{NaI}$ gamma spectrum of the site ID1, as an example.

After the identification of the radionuclide, the type of source was characterized. In this regard, a search for metal parts was carried out with a metal detector to exclude the presence of steel casings and drums and to support the hypothesis of free sources scattered in the area under investigation. The result of this search confirmed the absence of metal components, and then it was possible to exclude an important range of devices that contain radium, such as smoke detectors, heads of industrial appliances, pipes or ducts containing NORM in use in the phosphate or oil industry, etc. [25]. Phosphoric metasilicates, produced by a chemical industry in the Crotone municipality (about $140 \mathrm{~km}$ from the investigated area), and used in past years as filling materials for roads and for paving [26], were excluded because only a part of the asphalted road was affected by contamination, while in the other asphalted parts, only environmental background level was recorded.

Then, the area was immediately banned and classified as contaminated by radionuclides (RADREM — stage 4). The intervention to contain the radiological risk was performed through an activity of excavation of the road surface, aimed at recovering the radioactive source. The operations brought to light a total of eight sources of ${ }^{226} \mathrm{Ra}$. In particular, one, one half, two and almost five sources were found at the sites ID1, ID2, ID3 and ID4, respectively. They were without metal support, with some river stones and bitumen on it. In one of the discovered sources, it was possible to recognize the name of the manufacturing company, and therefore to trace back to the industrial device that hosted the sources of radium: a radioactive lightning rod with eight sources of ${ }^{226} \mathrm{Ra}$ [27].

The absorbed dose rate measured "at contact" with the bared radioactive sources and the total activity of ${ }^{226} \mathrm{Ra}$, quantified through Equation (2), are reported in Table 2 for each site ID. The gamma constant in air value of $2.23 \times 10^{-13} \mathrm{~Gy} \mathrm{~m}^{2} \mathrm{~h}^{-1} \mathrm{~Bq}^{-1}$ for ${ }^{226} \mathrm{Ra}$ and a distance between the source and the detector of $15 \mathrm{~cm}$ were employed for the calculation. 
Table 2. The absorbed dose rate measured at contact and the total activity of ${ }^{226} \mathrm{Ra}$ in the "hot spots" sites.

\begin{tabular}{ccc}
\hline Site ID & $\begin{array}{c}\dot{\boldsymbol{D}} \\
\left(\mu \mathbf{y ~ h}^{-\mathbf{1}}\right)\end{array}$ & $\begin{array}{c}\mathbf{2 2 6}_{\mathbf{R a}} \\
\text { Total Activity } \\
\mathbf{( M B q )}\end{array}$ \\
\hline 1 & $88 \pm 9$ & 8.8 \\
2 & $20 \pm 4$ & 2.2 \\
3 & $154 \pm 17$ & 15.4 \\
4 & $266 \pm 14$ & 26.4 \\
\hline
\end{tabular}

The discovery was managed by applying the legal provisions with regard to orphan sources, having found sources with activity higher than $10 \mathrm{kBq}$ [28].

\section{Conclusions}

Every year in Italy an unspecified number of radioactive sources are disposed of, almost all formally subjected to the appropriate administrative procedures, with the control bodies that are obliged to carry out the necessary checks. The life end of these sources is a legally codified phase, but the reality, as the case study reported in this article confirms, is quite different. Therefore, raising the levels of attention, also through the development and the application of a radiological risk containment procedure, is very useful for controlling the life cycle of a radioactive source.

In this paper, an innovative radiological risk containment procedure, called RADREM, was developed for the first time in the environmental field, for outdoor activities, with the aim to control the levels of environmental radioactivity and to contain the radiological risk in potentially contaminated areas.

RADREM was applied in an industrial area within the Calabrian territory, southern Italy. Its application allowed, first of all, the identification of an area of about $30 \mathrm{~m}^{2}$ surface, affected by an important anomaly in the value of the environmental radioactivity background. After that, it was possible to recognize, inside it, eight ${ }^{226} \mathrm{Ra}$ orphan sources buried under the road surface, and, finally, to develop all the actions in order to contain the radiological risk for the workers and the population. The systematic application of this procedure can in principle allow one to investigate the radioactive contamination of an industrial area, where this aspect is usually disregarded, and then to better assess the health risk for the workers and the population.

Author Contributions: Conceptualization, F.C. and V.V.; methodology, F.C. and V.C.; validation, D.M.; formal analysis, S.P.; investigation, F.C., M.I., G.P. and V.V.; resources, F.C., V.C. and D.M.; data curation, F.C.; writing-original draft preparation, F.C.; supervision, D.M., M.I. and V.V. All authors have read and agreed to the published version of the manuscript.

Funding: This research received no external funding.

Institutional Review Board Statement: Not applicable.

Informed Consent Statement: Not applicable.

Conflicts of Interest: The authors declare no conflict of interest.

\section{References}

1. Burk, R.J., Jr. State and Federal Action Is Needed for Better Control of Orphan Sources; Health Physics Society: Herndon, VA, USA, 2002.

2. IAEA. Control of Orphan Sources and Other Radioactive Material in the Metal Recycling and Production Industries; International Atomic Energy Agency: Vienna, Austria, 2012.

3. Janžekovi, H. Orphan Sources in Slovenia. In Proceedings of the International Conference Nuclear Energy for New Europe 2005, Bled, Slovenia, 5-8 September 2005; pp. 1-8.

4. IAEA. Strengthening Control over Radioactive Sources in Authorized Use and Regaining Control Over Orphan Sources; International Atomic Energy Agency: Vienna, Austria, 2004.

5. Caridi, F.; D’Agostino, M.; Belvedere, A.; Marguccio, S.; Belmusto, G. Radon radioactivity in groundwater from the Calabria region, south of Italy. J. Instrum. 2016, 11, P05012. [CrossRef] 
6. Caridi, F.; Messina, M.; D'Agostino, M. An investigation about natural radioactivity, hydrochemistry, and metal pollution in groundwater from Calabrian selected areas, southern Italy. Environ. Earth Sci. 2017, 76, 668. [CrossRef]

7. Caridi, F.; D’Agostino, M.; Messina, M.; Marcianò, G.; Grioli, L.; Belvedere, A.; Marguccio, S.; Belmusto, G. Lichens as environmental risk detectors. Eur. Phys. J. Plus 2017, 132, 189. [CrossRef]

8. Salmon, N.A. Indoor Full-Body Security Screening: Radiometric Microwave Imaging Phenomenology and Polarimetric Scene Simulation. IEEE Access 2020, 8, 144621-144637. [CrossRef]

9. Bouvet, M.; Thome, K.; Berthelot, B.; Bialek, A.; Czapla-Myers, J.; Fox, N.P.; Goryl, P.; Henry, P.; Ma, L.; Marcq, S.; et al. RadCalNet: A radiometric calibration network for earth observing imagers operating in the visible to shortwave infrared spectral range. Remote Sens. 2019, 11, 2401. [CrossRef]

10. Van Elmpt, W.; McDermott, L.; Nijsten, S.; Wendling, M.; Lambin, P.; Mijnheer, B. A literature review of electronic portal imaging for radiotherapy dosimetry. Radiother. Oncol. J. Eur. Soc. Ther. Radiol. Oncol. 2008, 88, 289-309. [CrossRef] [PubMed]

11. Caridi, F.; D’Agostino, M.; Belvedere, A.; Marguccio, S.; Belmusto, G.; Gatto, M.F. Diagnostics techniques and dosimetric evaluations for environmental radioactivity investigations. J. Instrum. 2016, 11, C10012. [CrossRef]

12. United Nations Scientific Committee on the Effects of Atomic Radiation. Sources and Effects of Ionizing Radiation: Report to the General Assembly, with Scientific Annexes; United Nations: New York, NY, USA, 2000; Volume I, ISBN 92-1-142238-8.

13. Bayramli, G. The environmental problems of Azerbaijan and the search for solutions. WSEAS Trans. Environ. Dev. 2020, 16, 423-433. [CrossRef]

14. Ramasamy, V.; Suresh, G.; Meenakshisundaram, V.; Ponnusamy, V. Horizontal and vertical characterization of radionuclides and minerals in river sediments. Appl. Radiat. Isot. 2011, 69, 184-195. [CrossRef] [PubMed]

15. Caridi, F.; Marguccio, S.; D'Agostino, M.; Belvedere, A.; Belmusto, G. Evaluation of radiological impacts from NORM: A case study. J. Instrum. 2018, 13, P08003. [CrossRef]

16. Laraia, M. Radioactive contamination and other environmental impacts of waste from nuclear and conventional power plants, medical and other industrial sources. Environmental Remediation and Restoration of Contaminated Nuclear and Norm Sites. In Environmental Remediation and Restoration of Contaminated Nuclear and Norm Sites; Woodhead Publishing: Sawston, UK, 2015; pp. 35-56. [CrossRef]

17. Ludlum-Measurements Ion Chamber Survey Meter 9 DP User Manual 2014. Available online: http://www.mdkjdq.com/Uploa dFiles/FCK/20130523151737_bqplww.pdf (accessed on 15 November 2021).

18. Shand, C.A.; Rosén, K.; Thored, K.; Wendler, R.; Hillier, S. Downward migration of radiocaesium in organic soils across a transect in Scotland. J. Environ. Radioact. 2013, 115, 124-133. [CrossRef] [PubMed]

19. Caresana, M. Carichi di Rottami Metallici-Rilevazione di Radionuclidi con Misure X e Gamma; UNI: Rome, Italy, 2016.

20. Canberra InSpector ${ }^{\mathrm{TM}} 1000$ User Manual 2004. Mirion Technologies (Canberra), Atlanta, USA. Available online: http:/ / www.old slcj.uw.edu.pl/ \{\}agniecha/por/InSpector100UserManual.pdf (accessed on 16 November 2021).

21. IAEA. Extent of Environmental Contamination by Naturally Occurring Radioactive Material (Norm) and Technological Options for Mitigation; IAEA: Vienna, Austria, 2003; pp. 1-208.

22. IAEA. Manual on Laboratory Testing for Uranium Ore Processing-Technical REPORTS Series n. 313; IAEA: Vienna, Austria, 1990.

23. Donnini, M.; Marchesini, I.; Zucchini, A. Geo-LiM: A new geo-lithological map for Central Europe (Germany, France, Switzerland, Austria, Slovenia, and Northern Italy) as a tool for the estimation of atmospheric $\mathrm{CO}_{2}$ consumption. J. Maps 2020, 16, 43-55. [CrossRef]

24. Available online: http://www.radia.apat.it (accessed on 5 November 2021).

25. EC (European Commission). RADIATION PROTECTION-Effluent and dose control from European Union NORM industries: Assessment of Current Situation and Proposal for a Harmonised Community Approach; Publications office of the European union: Bruxelles, Belgium, 2003; Volume 2, ISBN 9289463627.

26. Caridi, F.; Marguccio, S.; Durante, G.; Trozzo, R.; Fullone, F.; Belvedere, A.; D'Agostino, M.; Belmusto, G. Natural radioactivity measurements and dosimetric evaluations in soil samples with a high content of NORM. Eur. Phys. J. Plus 2017, 132, 56. [CrossRef]

27. Santos, P.D.O.; Silva, F. Management of Radioactive Disused Lightning Rods. In Proceedings of the 2013 International Nuclear Atlantic Conference-INAC 2013, Recife, PE, Brazil, 24-29 November 2013; ISBN 978-85-99141-05-2.

28. Italian Legislation D.Lgs. 101/20. Available online: https:/ / www.normattiva.it/atto/caricaDettaglioAtto?atto.dataPubblicazion eGazzetta=2020-08-12\&atto.codiceRedazionale=20G00121\&atto.articolo.numero=0\&atto.articolo.sottoArticolo=1\&atto.articol o.sottoArticolo1=10\&qId=0f26c68d-b09a-4b89-a802-a8b35cd2a300\&tabID=0.47489172538218827\&title=1bl.dettaglioAtto (accessed on 6 November 2021). 